\title{
Behavioral contrast in pigeons learning an auditory discrimination
}

\author{
G. WILLIAM FARTHING \\ University of Maine, Orono, Maine 04473
}

\begin{abstract}
After an initial period of nondifferential training, 14 pigeons were trained on a go/no-go discrimination between different click frequencies. Keypeck responses during the positive stimulus were reinforced with food on a 1-min variable interval schedule, whereas responses during the negative stimulus were extinguished and prolonged the negative stimulus for 30 sec (correction procedure). Response rates in the positive stimulus increased during discrimination training in all subjects. A control group given extended nondifferential training had significantly lower response rates and contrast ratios. The results are inconsistent with a simple autoshaping theory of behavioral contrast.
\end{abstract}

Positive behavioral contrast refers to the increase in the operant response rate that occurs during one component of a multiple schedule when the response rate in another component decreases, where the reinforcement schedule in the first component remains constant. A new explanation of positive contrast in terms of autoshaping has been suggested by Gamzu and Schwartz (1973; also cf. Hearst \& Jenkins, 1974; Rachlin, 1973). These autors have pointed out that the conditions which produce behavioral contrast in pigeons seem to be essentially the same as those which produce autoshaping (Brown \& Jenkins, 1968), the only critical difference in procedure being that reinforcement is dependent upon operant responses in the former case, but independent of responses in the latter. In both cases, the occurrence or nonoccurrence of food reinforcement is differentially correlated with two (or more) different external stimuli. According to the autoshaping theory, the additional responses which occur during the response rate increase in positive contrast are a direct result of the stimulus-food contingency, rather than the response-food contingency (cf. Redford \& Perkins, 1974).

The autoshaping theory of contrast predicts that contrast will occur only in those operant discrimination situations where autoshaping occurs when food is delivered independently of the subject's responses. Autoshaped keypecking does not occur when an auditory stimulus is paired with food, apparently because an auditory stimulus is relatively diffuse and not localized on the key (Schwartz, 1973). Therefore, the autoshaping theory would predict that positive contrast would not occur in an operant go/no-go auditory discrimination. Schwartz $(1974 ; 1975)$ has confirmed this prediction. The present study shows, however, that under some conditions positive contrast does occur in pigeons learning an auditory discrimination.

This research was supported by National Institute of Mental Health Grant No. 18290 to the author. Reprints may be obtained from the author at the Department of Psychology, 301 Little Hall, University of Maine, Orono, Maine 04473.

\section{METHOD}

\section{Subjects}

The subjects were 21 experimentally naive female Silver King pigeons $(5-8$ years old $)$, maintained at $75 \% \pm 15 \mathrm{~g}$ of their free-feeding body weights.

\section{Apparatus}

The birds were trained in a Lehigh Valley Electronics (Model 1519) pigeon test chamber, in which the key was located above the feeder opening in the center of the front panel, and the speaker was located about $13 \mathrm{~cm}$ to the left and $9 \mathrm{~cm}$ below the key. Auditory stimuli consisted of a train of clicks produced by a Foringer click generator. The physical intensity of the clicks was approximately $91 \mathrm{~dB}$ SPL, superimposed on a continuous white noise of $86 \mathrm{~dB}$. The key was transilluminated by red light. Reinforcers consisted of $3 \mathrm{sec}$ access to mixed grain. A houselight was on throughout each session.

\section{Procedure}

The keypeck response was initially shaped by the method of successive approximations, and every keypeck was reinforced (CRF) until 30 reinforcers had been collected, on each of 2 successive days. Through out the experiment, the keylight was on continuously except during the 3 -sec intervals during which food reinforcers were available. The click frequency to be used as $\mathrm{S}+$ was on throughout response shaping and CRF training. The S+ click frequency was 1.8 clicks/sec (pps) for 9 birds, and $6.6 \mathrm{pps}$ for twelve birds.

Following CRF training, all subjects received 11 to 15 (usually 14) sessions of nondifferential training with pecks reinforced on a variable-interval 1-min (VI 1-min) schedule. The S+ click was on continuously during these nondifferential VI sessions, which were of $60 \mathrm{~min}$ duration.

Following nondifferential VI training, 14 of the birds were trained on an auditory go/no-go discrimination with a correction procedure. In discrimination sessions, S+ (VI 1-min) and S(extinction) were presented in simple alternation, with 15 presentations of each stimulus in each session. The S+ duration was always $120 \mathrm{sec}$. The minimum $\mathrm{S}$-duration was $120 \mathrm{sec}$, but S- did not terminate until $30 \mathrm{sec}$ had elapsed without a peck response (correction procedure). There were no blackouts or timeouts between stimulus presentations. This discrimination procedure is like one used by Bloomfield (1966). Discrimination training continued until the bird achieved a criterion of two sessions (not necessarily consecutive) during which its response rate in $\mathrm{S}$ - was not more than $25 \%$ of its rate in $\mathrm{S}+$ (this calculation was based on data for only the first $90 \mathrm{sec}$ of S+ and $\mathrm{S}$ - periods). The discriminative stimuli were as follows: 


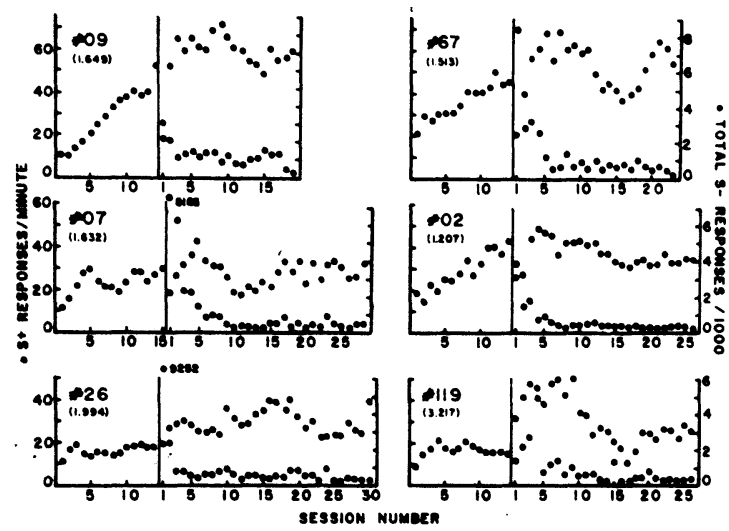

Figure 1. Acquisition data for pigeons trained to discriminate S+ 1.8 pps vs. S- 0.0 pps (no clicks). The vertical line on each graph separates the nondifferential training sessions from the discrimination sessions. Filled circles indicate the response rate (responses per minute) in S+, whereas the unfilled circles indicate the total number of responses in $\mathrm{S}$-during each session. The contrast ratio for each subject is shown in parentheses (see text). Where the total number of $S$ - responses exceeds the scale limit, the exact value is shown.

$S+1.8$ pps vs. $S-0.0$ pps, for six birds; $S+6.6$ pps vs. $S-1.8 \mathrm{pps}$, for four birds; and $S+6.6 \mathrm{pps}$ vs. $S-22.6 \mathrm{pps}$, for four birds.

After the initial 11-15 sessions of nondifferential VI training, the seven control group birds were given additional nondifferential VI training with sessions of only $30 \mathrm{~min}$ duration. For each bird in this group, nondifferential training continued for a number of sessions approximately equal to that of an arbitrarily matched discrimination bird with the same S+.

Following training, all subjects were given a generalization test on the click-frequency continuum (except Bird 119, which was dropped due to a procedural error in its 27 th discrimination session). Details of the test procedure have been presented elsewhere (Farthing \& Hearst, 1972, Experiments 3 and 4).

\section{RESULTS}

Training data for individual subjects in the discrimination group are presented in Figures 1, 2, and 3. Data for the nondifferentially trained control group are presented in Figures 4 and 5.

Most of the discrimination-trained subjects showed a clear-cut increase in response rate during discrimination training. In the control subjects, on the other hand, there was typically little

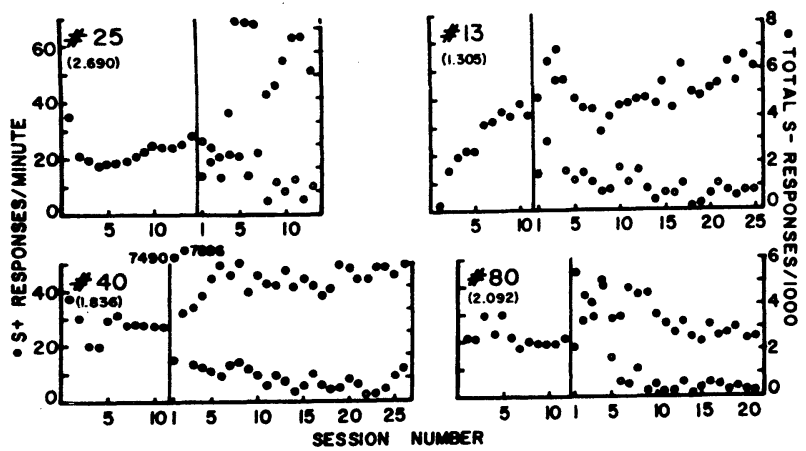

Figure 2. Acquisition data for pigeons trained to discriminate S+ 6.6 pps vs. S- 1.8 pps. See Figure 1 for explanation. increase in response rate during the second stage of nondifferential training (30-min sessions). Several of the discrimination subjects had a pattern of response rate change similar to that reported by Bloomfield (1966) with visual on-the-key discriminations and a correction procedure, where the response rate reached its maximum early in discrimination training and later declined. (See especially Birds 09, 67, 02, 119, 80, and 43.) This pattern might have been observed in more subjects if discrimination training had been continued longer (Terrace, 1966). Training was terminated when the subjects met the discrimination criterion, in order that all subjects could be given a generalization test when they were at about the same level of discrimination performance.

In demonstrations of behavioral contrast, it is desirable to return to the nondifferential baseline training condition, following discrimination training, in order to determine whether the response rate in $\mathrm{S}+$ will retum to its baseline level. This was not done in the present study since the subjects received a generalization test in extinction after they reached the discrimination criterion.

As an alternative means of providing a convincing demonstration of contrast, a quantitative comparison of the discrimination group with the control group was made. A contrast ratio was calculated for each subject: $B / A$, where $B$ is the highest response rate during any one of the first 10

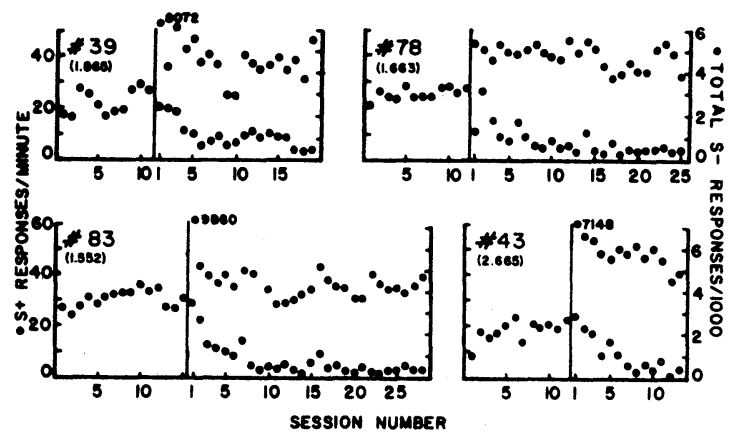

Figure 3. Acquisition data for pigeons trained to discriminate $S+6.6$ pps vs. S- 22.6 pps. See Figure 1 for explanation.

discrimination sessions (or the first 1030 -min nondifferential training sessions, for the control group), and $\mathrm{A}$ is the mean rate during the last three 60 -min nondifferential training sessions. The contrast ratio for each subject is shown in parentheses in Figures 1 through 5. The mean contrast ratio was 1.920 for the discrimination group, but only 1.348 for the control group, a significant difference $(t=2.457, d f=19, p<.025$ by a one-tailed test). Furthermore, the value of $B$ was significantly greater for the discrimination group than for the control group (means of 51.8 and 42.2 responses per minute, respectively, $t=1.775, p<.05)$, but the groups did not differ in the value of A (means of 28.8 and 32.2 , respectively, $t=.774$ ). The groups also differed significantly by several other possible contrast ratios. For example, if $\mathrm{A}$ is taken to be the highest rate during any one of the last five $60-\mathrm{min}$ nondifferential training sessions, the mean ratios for the discrimination and control groups are 1.776 and 1.179 , respectively $(t=2.747, p<.01)$.

There were no significant correlations between the total number of responses to $S$ - during the first 10 discrimination sessions and either the contrast ratio or the peak $S+$ response rate during discrimination training. The specific click frequencies used during training had no effect on either response rates or contrast ratios.

Cumulative records were available for the six birds whose data are shown in Figure 1. Each subject's record for the early 
discrimination session with the highest response rate (Session "B" in the contrast ratio) was subjected to occipital analysis in order to determine the pattern of responding during individual 2 -min $\mathrm{S}+$ periods. For the last $14 \mathrm{~S}+$ periods in that session, across all six subjects, approximately $34 \%$ of the S+ periods had a negatively accelerated pattern of responding, $11 \%$ had a positively accelerated pattern, and 55\% had either a constant rate or a variable rate which could not be clearly classified as either positive or negative acceleration.

The results of the generalization test along the click frequency continuum have been presented in detail elsewhere (Farthing \& Hearst, 1972, Experiments 3 and 4). In striking contrast to the results obtained by Williams (1973), all of the discrimination-trained birds showed clear-cut control by the click-frequency continuum, including those birds trained with $\mathrm{S}+1.8 \mathrm{pps}$ vs. $\mathrm{S}-$ no-click. Further, most of the discrimination-trained birds showed a peak shift effect. On the other hand, only one nondiscrimination bird (No. 36) showed clear-cut control by the click frequency continuum.

\section{DISCUSSION}

Schwartz (1974) reported a failure to find reliable positive contrast in three pigeons trained on an auditory discrimination between $\mathrm{S}+$ tone off vs. S- tone on. Also, he found no reliable contrast in four additional subjects which were trained to discriminate $\mathrm{S}+$ tone on vs. S- tone off (Schwartz, 1975). Schwartz interpreted his results as supporting an autoshaping theory of contrast. In the present study, on the other hand, positive contrast did occur in pigeons learning an auditory discrimination. The most striking difference in procedure between the two experiments is that the present experiment employed a correction procedure, whereas Schwartz used a noncorrection procedure. In a correction procedure, responses during a $\mathrm{S}_{-}$- period increase the duration of $\mathrm{S}_{-}$, whereas in a noncorrection procedure, a $S$ - period terminates after a fixed time interval, independently of responding. The use of a correction or noncorrection procedure might be a critical variable affecting contrast. Unfortunately, there seem to be no published reports where this variable has been systematically studied within a single experiment.

It may be that contrast will occur reliably in pigeons during discrimination training with a correction procedure, regardless of the nature of the stimuli, whereas contrast may ordinarily occur with a noncorrection procedure only if visual stimuli localized

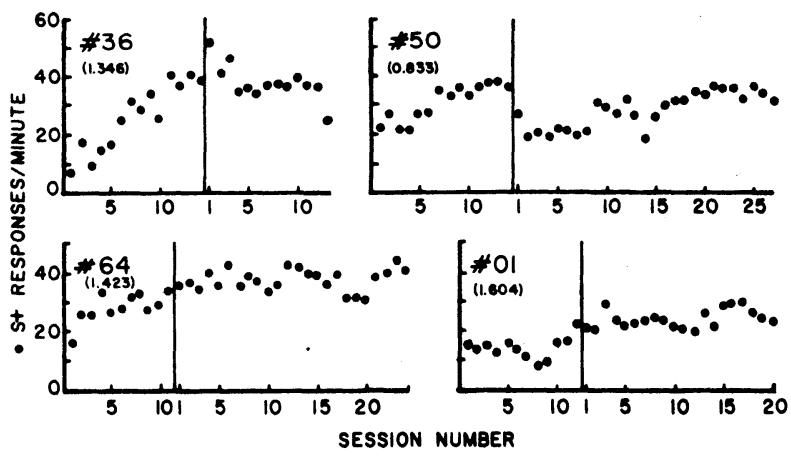

Figure 5. Acquisition data for pigeons given extended nondifferential training with $S+6.6$ pps. See Figure 4 for explanation.

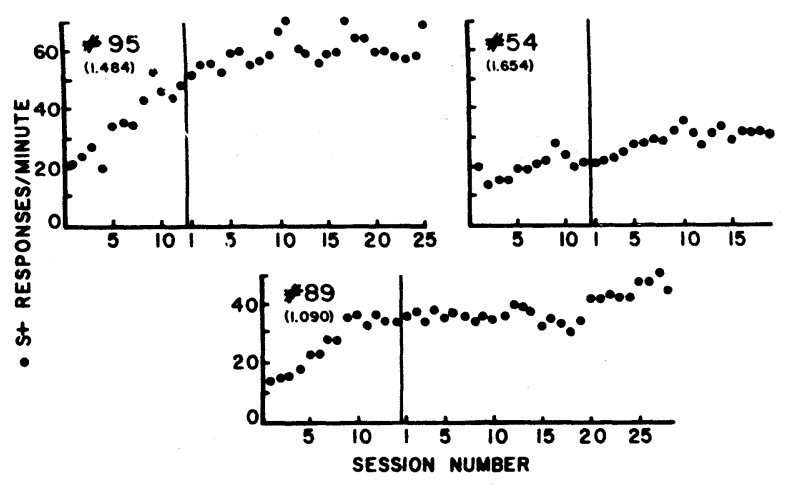

Figure 4. Acquisition data for pigeons given extended nondifferential training with $\mathrm{S}+1.8 \mathrm{pps}$. The vertical line on each graph separates the 60-min training sessions from the subsequent 30 -min sessions. The contrast ratio for each subject is shown in parentheses (see text).

on the response key are used as discriminative stimuli. Perhaps the autoshpaing theory of contrast adequately accounts for the changes in response rate when a noncorrection discrimination procedure is used, but other causal factors may be involved in producing the effects which occur with a correction discrimination procedure (e.g., cf. Bloomfield, 1966; Terrace, 1966).

\section{REFERENCES}

Bloomfield, T. M. Two types of behavioral contrast in discrimination learning. Journal of the Experimental Analy sis of Behavior, 1966, 9, 155-161.

Brown, P. L., \& Jenkins, H. M. Autosh aping of the pigeon's key peck. Joumal of the Experimental Analysis of Behavior, 1968, 11, 1-8.

Farthing, G. W., \& Hearst, E. Stimulus generalizations and discrimination along the click-frequency (flutter) continuum in pigeons. Perception and Psy chophysics, 1972, 12, 176-182.

Gamzu, E., \& Schwartz, B. The maintenance of key pecking by stimulus-contingent and response-independent food presentation. Journal of the Experimental Analysis of Behavior, 1973, 19,65-72.

Hearst, E., \& Jenkins, H. M. Sign-tracking: The stimulus-reinforcer relation and directed action. Austin, Texas: The Psy chonomic Society, 1974. (monograph)

Rachlin, H. Contrast and matching. Psy chological Review, 1973, 80, $217-234$.

Redford, M. E., \& Perkins, C. C. The role of autopecking in behavioral contrast. Journal of the Experimental Analy sis of Behavior, 1974, 21, 145-150.

Schwartz, B. Maintenance of key pecking by response-independent food presentation: The role of the modality of the signal for food. Journal of the Experimental Analy sis of Behavior, 1973, 20, 17-22.

Schwartz, B. Behavioral contrast in the pigeon depends upon the location of the stimulus. Bulletin of the Psy chonomic Society, $1974,3,365-368$.

Schwartz, B. Discriminative stimulus location as a determinant of positive and negative behavioral contrast in the pigeon. Journal of the Experimental Analy sis of Behavior, 1975, 23, 167-176.

Terrace, H. S. Behavioral contrast and the peak shift: Effects of extended discrimination training. Journal of the Experimental Analysis of Behavior, 1966, 9, 613-617.

Williams, B. A. The failure of stimulus control after presence-absence discrimination of click rate. Journal of the Experimental Analy sis of Behavior, 1973, 20, 23-27.

(Received for publication April 2, 1975.) 